\title{
Desempenho e composição da carcaça de cordeiros deslanados terminados em confinamento com diferentes dietas
}

\author{
José Teodorico de Araújo Filho ${ }^{1}$, Roberto Germano Costa ${ }^{2}$, Angelina Bossi Fraga ${ }^{3}$, Wandrick \\ Hauss de Sousa ${ }^{4}$, Marcílio Fontes Cezar ${ }^{5}$, Ana Sancha Malveira Batista ${ }^{6}$ \\ ${ }^{1}$ CECA - UFAL, Alagoas. Bolsista FAPEAL. \\ 2 CCA - UFPB, Paraíba. \\ ${ }^{3}$ CECA - UFAL, Alagoas. \\ ${ }^{4}$ EMEPA, Paraíba. \\ 5 UAMVICSTR - UFCG, Paraíba. \\ ${ }^{6} D Z-U V A$, Ceará.
}

RESUMO - Este trabalho foi realizado com os objetivos de avaliar os efeitos da alimentação e do genótipo sobre as características quantitativas de carcaça de cordeiros terminados em confinamento e estimar sua margem bruta. Foram utilizados 18 cordeiros de cada genótipo: Morada Nova, Santa Inês e mestiços Dorper $\times$ Santa Inês. As rações foram constituídas de 2,5 Mcal EM/kg MS e 2,94 Mcal EM/kg MS. Utilizou-se um delineamento inteiramente casualizado, em esquema fatorial $3 \times 2$. As dietas influenciaram o ganho de peso diário, o peso de corpo vazio, o escore corporal, a eficiência alimentar e o tempo de confinamento, enquanto o genótipo promoveu diferenças em todas as variáveis estudadas. A densidade calórica das dietas influenciou os rendimentos biológicos, de carcaça quente e fria, esses dois últimos influenciados pelos genótipos. A dieta mais energética (2,94 Mcal EM/kgMS) proporcionou maiores pesos absolutos de pescoço, paleta, costela, lombo e perna, porém, em valores relativos, cordeiros alimentados com diferentes níveis energéticos não diferiram quanto a essas características, independentemente do nível energético da dieta. Os rendimentos percentuais dos cortes foram influenciados pelos genótipos, exceto o corte pescoço. Os pesos de todos os cortes foram influenciados pelos genótipos. A maior margem bruta de carcaça foi obtida com ração de maior nível energético.

Palavras-chaves: carcaça ovina, densidade energética, raças

\section{Performance and carcass composition of shorn lambs finished in a feedlot on different diets}

\begin{abstract}
This study was performed with the objective of assessing the effects of feed and genotype on the quantitative characteristics of carcasses of lambs finished in a feedlot and estimate gross margins. Eighteen lambs of each genotype were used: Morada Nova, Santa Inês and cross-breed Dorper $\times$ Santa Inês. Feeds with low and high energetic levels consisted of 2.5 Mcal ME/kg DM and 2.94 Mcal ME/kg DM, respectively. A randomized complete design was used, with a $3 \times 2$ factorial scheme. The diets influenced daily weight gain, empty body weight, body score, feed efficiency and feedlot days, whilst the genotype promoted differences in all the variables studied. The caloric density of the diets influenced the biological hot and cold carcass yields, and the latter two were influenced by genotype. The more energetic diet ( $2.94 \mathrm{Mcal} \mathrm{EM} / \mathrm{kgDM})$ resulted in higher absolute weights of neck, shoulder, rib, loin and leg, but, in relative values, lambs fed with different energetic levels did not differ for these characteristics, regardless of the energetic level of the diet. The percentage yield of the cuts was influenced by the genotypes, except for the neck. The weights of all the cuts were influenced by genotypes. The treatment with the highest energy level resulted in the largest gross margin.
\end{abstract}

Key Words: carcass yield, dry matter consumption, sheep

\section{Introdução}

A criação de ovinos deslanados no Nordeste apresenta baixos índices zootécnicos em comparação a outras regiões, fato associado ao regime pluviométrico, que é escasso e irregular na região.
A prática das atividades pecuárias desenvolvidas no País tem comprovado que a obtenção de índices produtivos satisfatórios é possível com a utilização de genótipos apropriados submetidos ao manejo alimentar adequado.

As raças ovinas especializadas para corte apresentam crescimento rápido e bom acabamento de carcaça, mas são 
exigentes em alimentação e manejo sanitário. Por outro lado, os ovinos nativos, embora deixem a desejar em acabamento de carcaça, possuem notável adaptabilidade às condições do semiárido, predominantes no Nordeste. Entre eles, podem ser citadas as raças Santa Inês e Morada Nova.

Além do recurso genético, o manejo alimentar constitui fator limitante para produção de carne ovina no Nordeste, pois é um dos principais componentes dos sistemas de produção. A crescente procura por produtos oriundos da ovinocultura requer melhorias nos desempenhos produtivos do rebanho, exigindo, dessa forma, estudos que possibilitem estabelecer quantidades de energia que atendam às necessidades desses animais, observando-se o tipo de alimento empregado, pois o melhor desempenho de ovinos depende do potencial do animal e da elaboração de dietas mais eficientes (Alves et al., 2003).

O estudo de carcaças é uma avaliação de parâmetros relacionados com medidas objetivas e subjetivas e deve estar ligado aos aspectos e atributos inerentes à porção comestível. A ovinocultura tem como meta principal a obtenção de animais capazes de direcionar grandes quantidades de nutrientes para a produção de músculos, uma vez que esse tecido reflete a porção comestível (Santos \& Pérez, 2000).

Objetivou-se avaliar as características de carcaça de ovinos de diversos grupos genéticos terminados em confinamento com dietas contendo dois níveis de energia e comparar, por meio de uma análise econômica, a margem bruta dos genótipos e das dietas.

\section{Material e Métodos}

Este estudo foi conduzido na Estação Experimental de Pendência, pertencente à Empresa Estadual de Pesquisa Agropecuária da Paraíba-EMEPA, localizada no município de Soledade - PB, na meso-região do Curimataú, situada na Latitude $7^{\circ} 8^{\prime} 18^{\prime \prime}$ S e Longitude $36^{\circ} 27^{\prime}$ 2", W do Meridiano de Greenwich, com altitude de $534 \mathrm{~m}$ e temperatura média de $30^{\circ} \mathrm{C}$ e umidade relativa do ar média de $70,13 \%$.

Foram utilizados 54 cordeiros das raças Morada Nova, Santa Inês e mestiços Dorper $\times$ Santa Inês, 18 animais de cada genótipo. Os animais da raça Morada Nova tinham aproximadamente 150 dias de idade e pesavam 14,98 \pm $2,80 \mathrm{~kg}$. Os genótipos Santa Inês e Dorper $\times$ Santa Inês estavam com idade média de 100 dias e peso médio de $17,63 \pm 1,48$ e 17,80 $\pm 1,52 \mathrm{~kg}$, respectivamente.

O período de adaptação às baias e às dietas foi de 14 dias, durante o qual os animais foram vacinados contra clostridiose, vermifugados por via oral com vermífugo à base de moxidectina a $1 \%$, com repetição 15 dias após a primeira. Para controle de eimeriose foi utilizada sulfaquinoxalina sódica $25 \mathrm{~g}$ durante quatro dias.

Duas rações concentradas foram formuladas com base no NRC (1985) para ganhos diários de $250 \mathrm{~g} / \mathrm{dia}$, e contendo dois níveis de energia: uma com menor nível de energia (2,50 Mcal EM/kg MS) e a outra com maior nível (2,94 Mcal $\mathrm{EM} / \mathrm{kg} \mathrm{MS}$ ). A base do volumoso foi feno de capim-tifton 85 (Cynodon dactylon), triturado em máquina forrageira, com redução das partículas para 1 a $2 \mathrm{~cm}$. A ração foi constituída de farelo de soja, milho, ureia, sal mineral e farelo enriquecido de palma. Para obtençãodo farelo enriquecido de palma, utilizam-se processo fermentativo e a ação de microrganismos em presença de uma mistura mineral, preparado segundo Tabosa et al. (2006) (Tabela 1).

Os animais foram distribuídos em grupos de três por baia, com acesso livre aos comedouros e bebedouros, onde permaneceram em regime de confinamento até atingirem aproximadamente $30 \mathrm{~kg}$ de peso vivo. Os cordeiros receberam as dietas à vontade de forma a permitir $20 \%$ de sobras, durante toda a fase experimental, fornecidas duas vezes ao dia, às $7 \mathrm{~h}$ e às $15 \mathrm{~h}$. $\mathrm{O}$ consumo de matéria seca foi determinado quantificando-se a oferta e as sobras, diariamente, durante todo o período experimental e, com essa informação, foi calculada a eficiência alimentar.

Ao atingirem o peso de abate, os animais foram pesados para determinação dos pesos vivos sem jejum (PV) e, em seguida, foram submetidos a um período de jejum de sólidos com dieta hídrica por 16 horas. Antes de serem abatidos, foram novamente pesados para obtenção do peso vivo ao abate (PVA).

O escore corporal foi avaliado da forma como realizado por Cezar \& Souza (2007), após alguns ajustes da metodologia. Adotou-se o intervalo de 1 a 5 , variando em 0,5 ponto, sendo: escore 1 - animais muito magro ou emaciados; escore 2 - animais magros; escore 3 - animais moderados; escore 4 - animais gordos; escore 5 - animais muito gordos ou obesos.

O processo de abate foi iniciado com atordoamento por concussão cerebral, seguido de sangria, esfola e evisceração. O sangue foi coletado e o trato gastrintestinal (TGI) retirado, pesado e, após a retirada de seu conteúdo, realizada nova pesagem para determinação do trato gastrintestinal vazio (TGIV). Foi determinado o peso de corpo vazio (PCV), definido como o peso vivo ao abate menos o somatório do conteúdo gastrintestinal, urina e suco biliar: PCV $=$ PVA $-[($ TGIC - TGIV $)+$ urina + suco biliar]. 
Tabela 1 - Composição das rações experimentais

\begin{tabular}{lcc}
\hline Ingrediente $(\%)$ & & Dieta \\
\cline { 2 - 3 } & 2,50 Mcal EM/kgMS & 2,94 Mcal EM/kgMS \\
\hline Farelo de milho & 25,00 & 50,50 \\
Farelo de soja & 10,00 & 15,00 \\
Farelo enriquecido de palma & 33,00 & 14,00 \\
Feno de capim-tifton & 30,50 & 19,00 \\
Ureia & 1,00 & 1,00 \\
Sal mineral ${ }^{1}$ & 0,50 & 0,50 \\
Composição bromatológica (\%) & & 90,37 \\
Matéria seca & 90,89 & 13,23 \\
Matéria mineral (\%MS) & 14,50 & 19,65 \\
Proteína bruta (\% MS) & 18,64 & 33,57 \\
Fibra em detergente neutro (\%MS) & 41,72 & 13,70 \\
Fibra em detergente ácido (\%MS) & 19,63 & 81,66 \\
Nutrientes digestíveis totais & 69,44 & 2,95 \\
Extrato etéreo (\%) & 2,32 & \\
\hline
\end{tabular}

${ }^{1}$ Cada porção de 1.000 g contém: Ca - 140,0 g; P - 65,0 g; S - 15,0 g; Mg - 15,0 g; Zn - 3.500,0 mg; Mn - 3.000,0 mg; I - 60,0 mg; Se - 10,0 mg; Co - 100,0 mg; vit. A - 50.000,0 UI; flúor (Máximo) - 650,0 mg.

Após a retirada da cabeça e das extremidades dos membros, as carcaças foram pesadas, obtendo-se o peso de carcaça quente (PCQ) e o rendimento de carcaça quente $(\mathrm{RCQ}=\mathrm{PCQ} / \mathrm{PVA} \times 100)$ e o rendimento biológico ou verdadeiro $(\mathrm{RB}=\mathrm{PCQ} / \mathrm{PCV} \times 100)$.

As carcaças foram resfriadas por 24 horas a $\pm 4{ }^{\circ} \mathrm{C}$ e penduradas pelo tendão calcâneo em ganchos apropriados, e com distância de $17 \mathrm{~cm}$ entre as articulações. Ao final desse período, foram registrados os pesos de carcaça fria (PCF) e calculado o rendimento de carcaça fria $(\mathrm{RCF}=\mathrm{PCF} / \mathrm{PVA} \times 100)$.

A eficiência alimentar foi determinada pela relação entre o ganho de peso do período e a quantidade de matéria seca consumida.

As carcaças foram divididas longitudinalmente, na altura da linha média, em dois antíneros, e a parte direita seccionada em cinco regiões anatômicas (COLOMERROCHER et al., 1986), que foram pesadas individualmente. Essas regiões compreendem (Figura 1):

- perna: base óssea que abrange a região do ilíaco (ílio), ísquio, púbis, vértebras sacrais, as duas primeiras vértebras coccígeas, fêmur, tíbia e tarso, obtida por corte perpendicular à coluna entre a última vértebra lombar e a primeira sacra;

- lombo: compreende a região das vértebras lombares, obtido perpendicularmente à coluna, entre a $13^{\text {a }}$ vértebra dorsal-primeira lombar e última lombar-primeira sacra;

- costelas: compreende as 13 vértebras torácicas, com as costelas correspondentes e o esterno;

- paleta: região que compreende a escápula, o úmero, o rádio, a ulna e o carpo;

- pescoço: refere-se às sete vértebras cervicais; é obtido por corte oblíquo entre a sétima cervical e a primeira torácica.
Para os cálculos da margem bruta, tomaram-se como base o ganho de peso total no período de confinamento, o preço por quilograma praticado na região, o consumo total de matéria seca, o preço por quilograma da matéria seca e as despesas com vacinas e medicamentos. Para o farelo de palma enriquecido, foi considerado o custo divulgado por

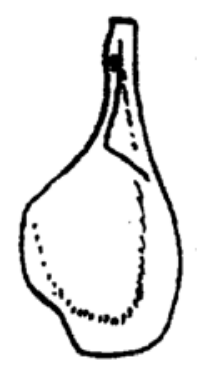

Paleta

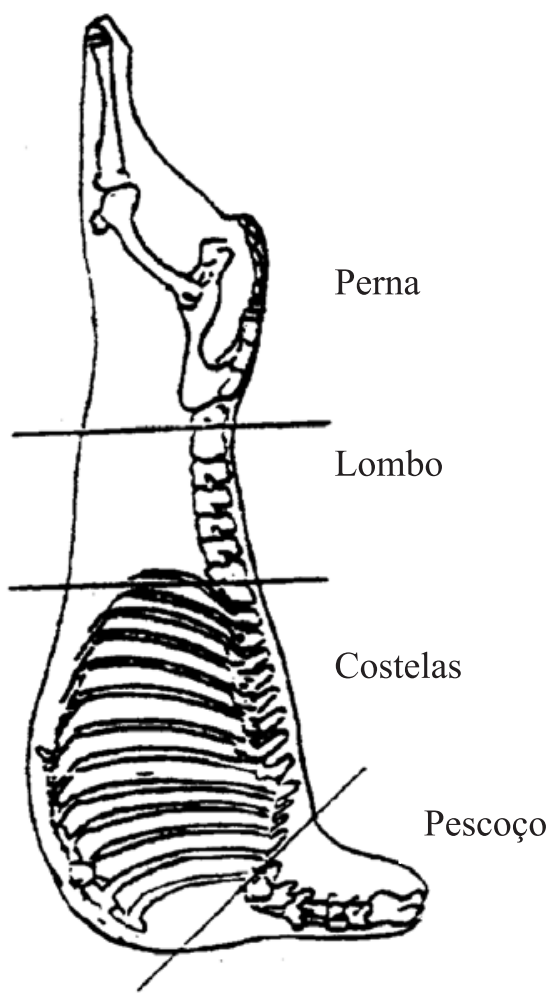

Fonte: Gonzaga Neto et al. (2006)

Figura 1 - Cortes cárneos, efetuados na meia-carcaça dos cordeiros, segundo as regiões anatômicas: paleta, perna, lombo, costelas e pescoço. 
Tabosa et al. (2006). Esses cálculos foram adaptados de Véras et al. (2005) e a margem bruta foi determinada pela seguinte equação:

Margem bruta $=$ ganho de peso $\times 3,00-($ CMStotal $\times$ Preco kg dieta) - DVM, em que:

$3,00=$ preço $(\mathrm{R} \$)$ por $\mathrm{kg}$ do cordeiro vivo praticado na região e localidades próximas

CMStotal $=$ consumo de matéria seca total

$\mathrm{DVM}=$ despesas com vacinas e medicamentos

O delineamento experimental adotado foi o inteiramente casualizado num esquema fatorial $3 \times 2$ (três genótipos e duas dietas). Foram realizadas análises de variâncias para as variáveis estudadas, utilizando-se o procedimento (GLM) do SAS ${ }^{\circledR}$ (1996), cujo modelo incluiu os efeitos de dieta (dois níveis de energia), genótipo animal (Morada Nova, Santa Inês e mestiço Dorper $\times$ Santa Inês), além da covariável peso ao abate: $Y_{i j k}=\mu+d_{i}+g_{j}+\beta\left(X_{i j k}-X\right)+\varepsilon_{i j k}$, em que: $\mathrm{Y}_{\mathrm{ijk}}=$ valor observado da característica; $\mu=$ média geral; $\mathrm{d}_{\mathrm{i}}$ $=$ efeito da $\mathrm{i}$-ésima dieta $(\mathrm{i}=1,2) ; \mathrm{g}_{\mathrm{j}}=$ efeito do $\mathrm{j}$-ésimo genótipo $(j=1,2,3) ; \beta=$ coeficiente de regressão linear, em relação ao peso ao abate $X_{\mathrm{ijk}}$; $X_{\mathrm{ijk}}=$ peso vivo de abate; $\mathrm{X}=$ média do peso vivo ao abate; $\varepsilon_{\mathrm{ijk}}=$ erro aleatório associado a cada observação.

Para o estudo das variáveis incluídas no modelo matemático, foram testados os efeitos de todas as possíveis interações e, como não apresentaram significância estatística ( $\mathrm{P}>0,05)$, não foram incluídos nas análises. As médias dos tratamentos foram comparadas pelo teste de Tukey a $5 \%$ de probabilidade.

\section{Resultados e Discussão}

O ganho de peso diário (GPD) foi influenciado $(\mathrm{P}>0,05)$ pela densidade energética das dietas (Tabela 2) e foi $14,28 \%$ maior nos animais alimentados com a dieta com maior densidade energética.

Os genótipos apresentaram diferenças $(\mathrm{P}<0,05)$ quanto ao ganho de peso diário, que foi semelhante $(\mathrm{P}>0,05)$ entre os genótipos Santa Inês e Dorper $\times$ Santa Inês e 7,14 e $14,71 \%$ superior, respectivamente, ao da raça Morada Nova. Esse resultado mostrou dois aspectos importantes: o primeiro foi a evidência de superioridade em ganho de peso diário do genótipo Santa Inês em relação ao Morada Nova, uma vez que aquela raça é considerada de porte maior. O outro aspecto foi a semelhança em potencial de ganho de peso diário entre animais puros Santa Inês e os mestiços, que indica ausência de efeito da heterose para essa característica.

Para a variável peso do corpo vazio, as dietas diferiram significativamente $(\mathrm{P}<0,05)$ e aquela com menor densidade energética proporcionou peso de corpo vazio $8,64 \%$ menor que o obtido com a dieta com maior densidade de energia, provavelmente em decorrência do maior tamanho e da maior capacidade de ingestão do trato gastrintestinal dos animais mantidos com aquela dieta.

$\mathrm{O}$ peso do corpo vazio não diferiu $(\mathrm{P}>0,05)$ entre genótipos, fato que pode ser atribuído ao peso final de abate entre os genótipos, semelhantes entre si, proporcionando a mesma capacidade de ingestão e armazenamento.

O consumo de matéria seca não diferiu entre as dietas $(\mathrm{P}>0,05)$, possivelmente em decorrência da proximidade dos níveis de energia utilizados nesta pesquisa. Resultados semelhantes foram divulgados por Alves et al. (2003), que, trabalhando com cordeiros da raça Santa Inês e dietas com três níveis energéticos $(2,42 ; 2,66$ e 2,83 Mcal EM/kg MS), verificaram que as concentrações energéticas das dietas não influenciaram o consumo de matéria seca.

Os consumos de matéria seca foram semelhantes entre as raças Morada Nova e Santa Inês, cujos valores diferiram $(\mathrm{P}<0,05)$ dos apresentados pelo genótipo Dorper $\times$ Santa Inês. Os consumos das raças Morada Nova e Santa Inês foram 8,8 e $5,3 \%$ menores que o do genótipo Dorper $\times$ Santa Inês. Os resultados de consumo obtidos neste trabalho estão de acordo com o preconizado pelo NRC (1985) para essa categoria animal, que varia de 1,0 a $1,3 \mathrm{~kg} /$ dia. Entretanto,

Tabela 2 - Desempenho e dias em confinamento de ovinos das raças Morada Nova, Santa Inês e Dorper $\times$ Santa Inês alimentados com rações com duas densidades energéticas

\begin{tabular}{|c|c|c|c|c|c|c|}
\hline \multirow[t]{2}{*}{ Características } & \multicolumn{2}{|c|}{ Dieta (Mcal EM/kgMS) } & \multicolumn{3}{|c|}{ Genótipo } & \multirow{2}{*}{$\begin{array}{c}\text { Coeficiente } \\
\text { de variação(\%) }\end{array}$} \\
\hline & 2,50 & 2,94 & Morada Nova & Santa Inês & Dorper $\times$ Santa Inês & \\
\hline Peso inicial (kg) & 16,56 & 17,05 & $14,98 b$ & $17,63 \mathrm{a}$ & $17,80 \mathrm{a}$ & 11,47 \\
\hline Peso de abate (kg) & 28,61 & 29,62 & 28,53 & 29,09 & 29,72 & 7,53 \\
\hline Ganho de peso diário $(\mathrm{kg})$ & $0,180 \mathrm{~b}$ & $0,210 \mathrm{a}$ & $0,174 b$ & $0,210 \mathrm{a}$ & $0,201 \mathrm{a}$ & 15,15 \\
\hline Peso de corpo vazio (kg) & $23,84 b$ & $25,90 \mathrm{a}$ & 24,82 & 24,59 & 25,02 & 6,80 \\
\hline Consumo de matéria seca $(\mathrm{kg} / \mathrm{dia})$ & 1,09 & 1,07 & $1,04 b$ & $1,08 b$ & $1,14 \mathrm{a}$ & 11,44 \\
\hline Escore corporal & $3,23 b$ & $3,55 \mathrm{a}$ & $3,58 \mathrm{a}$ & $2,92 b$ & $3,68 \mathrm{a}$ & 11,22 \\
\hline Eficiência alimentar (\%) & $12,86 b$ & $15,87 \mathrm{a}$ & 13,55 & 14,92 & 14,62 & 17,77 \\
\hline Dias de confinamento & $69,89 \mathrm{a}$ & $61,33 b$ & $79,89 \mathrm{a}$ & $56,44 b$ & $60,50 \mathrm{~b}$ & 20,67 \\
\hline
\end{tabular}

Médias seguidas de letra diferentes na mesma linha diferem significativamente entre si pelo teste de Tukey a 5\% de probabilidade. 
essa ingestão não assegurou o ganho esperado de $250 \mathrm{~g}$ /dia, que, neste trabalho, foi de 174,210 e $201 \mathrm{~g}$ /dia para os genótipos Morada Nova, Santa Inês e mestiços Dorper $\times$ Santa Inês, respectivamente.

O consumo de matéria seca observado neste trabalho foi semelhante ao obtido por Cartaxo et al. (2009), que trabalharam com os genótipos Santa Inês e mestiços Dorper $\times$ Santa Inês submetidos a dietas com 2,70 Mcal $\mathrm{EM} / \mathrm{kg}$ MS. Esses autores verificaram consumo de 1,12 kg/ dia para a raça Santa Inês e de 1,06 kg/dia para o genótipo Dorper $\times$ Santa Inês. Essa semelhança no consumo pode ser atribuída à proximidade do nível energético das dietas utilizadas. Por outro lado, o consumo de matéria seca foi maior que o encontrado por Alves et al. (2003) em cordeiros da raça Santa Inês, cujo consumo médio foi de $0,88 \mathrm{~kg} / \mathrm{dia}$. Véras et al. (2005), por sua vez, trabalhando com mestiços Santa Inês, verificaram consumo de matéria seca superior aos obtidos neste trabalho, apresentando variação de 1,10 a 1,19 kg/dia, com GPD variando de 0,21 a $0,12 \mathrm{~kg} / \mathrm{dia}$.

O escore corporal, reflexo do estado de acabamento da carcaça, foi influenciado $(\mathrm{P}<0,05)$ pelos níveis energéticos da dieta, com um aumento para os animais alimentados com a dieta mais calórica. Essa diferença pode ser atribuída à maior velocidade de crescimento dos tecidos musculares e adiposos, promovido pelo maior aporte de energia da dieta a que esses animais estavam submetidos. Quanto aos genótipos, os valores médios observados para raça Morada Nova e os mestiços Dorper $\times$ Santa Inês foram semelhantes entre si e diferiram da média da raça Santa Inês que apresentou o menor escore.

O menor escore apresentado pela raça Santa Inês deve-se ao maior porte da raça, que, apesar de apresentar peso final semelhante aos outros dois genótipos, tem composição tecidual com maior percentual de tecido ósseo, com maior distribuição dos outros tecidos em uma estrutura de maior porte.

A eficiência alimentar foi influenciada $(\mathrm{P}<0,05)$ pelos níveis energéticos das dietas, observando-se maior ganho por unidade de matéria seca ingerida para animais alimentados com dietas mais concentradas energeticamente. Essa maior eficiência alimentar pode ser atribuída à melhor relação energia:proteína da dieta, sobretudo em animais em fase de crescimento.

Resultados semelhantes ao deste estudo foram encontrados por Véras et al. (2005) ao avaliarem o desempenho e as características de carcaça de ovinos alimentados com dietas contendo quatro níveis de substituição do milho moído pelo farelo de palma, em que a conversão alimentar variou de 5,71 até 10,07.
Os três grupos genéticos apresentaram eficiência alimentar semelhante $(\mathrm{P}>0,05)$. Cartaxo et al. (2009), trabalhando com os genótipos Santa Inês e mestiços Dorper $\times$ Santa Inês, também não encontraram diferença significativa entre eles para conversão alimentar. Furusho-Garcia et al. (2000) avaliaram a eficiência alimentar em genótipos Santa Inês puros, mestiços Santa Inês $\times$ Texel e mestiço Texel $\times$ Bergamacia enão encontraram diferença significativa $(\mathrm{P}>0,05)$ para conversão alimentar entre os genótipos estudados.

Dietas e genótipos influenciaram $(\mathrm{P}<0,05)$ o número de dias de confinamento. Os animais submetidos à dieta mais calórica permaneceram em média 8,56 dias a menos no confinamento que aqueles submetidos à alimentação de menor densidade energética, comprovando que dietas com maior densidade energética proporcionam maior velocidade no desenvolvimento dos tecidos.

Entre os grupos genéticos, o Morada Nova foi o que apresentou maior média aos 79 dias e foi significativamente diferente $(\mathrm{P}<0,05)$ dos outros dois grupamentos genéticos. Essa diferença foi de 23 dias para a raça Santa Inês e 19 dias para os mestiços Dorper $\times$ Santa Inês. Não obstante, o genótipo Morada Nova necessitou maior período de confinamento, convém ressaltar que essa raça é de menor porte, portanto, mais leve. Na presente pesquisa esse genótipo teve seu peso corporal aumentado de $14,98 \mathrm{~kg}$ no início do experimento para $28,53 \mathrm{~kg}$ no final, o que representa aumento de $90,39 \%$, enquanto, nos outros dois genótipos, o peso corporal aumentado em $65,00 \%$ e $66,97 \%$ para o Santa Inês e mestiço Dorper $\times$ Santa Inês, respectivamente. Huidobro et al. (2000) afirmaram que cada raça possui um peso adulto distinto, por isso, o genótipo determina diferentes velocidades no desenvolvimento dos grupos de tecidos.

A dieta com maior densidade energética proporcionou rendimento biológico superior $(\mathrm{P}<0,05)$ ao obtido com a dieta menos calórica, provavelmente em razão da maior velocidade no crescimento do tecido da carcaça (Tabela 3 ). Segundo Cézar (2004), o rendimento biológico, por não considerar os pesos do conteúdo gastrintestinal, urina e vesícula, é o que melhor representa os componentes do corpo, porém, o rendimento verdadeiro é o mais utilizado pelos produtores. O rendimento de carcaça fria, no entanto, é o mais praticado pelos frigoríficos e mais importante para a cadeia produtiva da carne ovina.

Sañudo \& Sierra (1986) afirmaram que o rendimento de carcaça fria varia entre 40 e $60 \%$ e que essa variação ocorre de acordo com a raça, os cruzamentos e com o sistema de produção, portanto, é maior em animais confinados e em produtos de cruzamentos quando se utilizam raças especializadas para carne. 
O rendimento biológico neste estudo apresentou valor médio de 57,24\% para os diferentes genótipos. Resultado de magnitude similar foi descrito por Cézar (2004), que trabalhou com cordeiros da raça Santa Inês e mestiços Dorper $\times$ Santa Inês e encontraram valor médio de 57,46\%; e Neres et al. (2001), trabalhando com duas formas de apresentação das rações (farelada e peletizada), encontraram média de 57,51\% de rendimento biológico. Por outro lado, o rendimento biológico neste estudo foi superior aos encontrados por Cartaxo et al. (2009), de 47,63\%, e Almeida Jr. et al. (2004), de $54,54 \%$ em cordeiros da raça Suffolk. Esses menores rendimentos podem ser atribuídos aos animais com grau de acabamento de carcaça inferior em relação aos animais desta pesquisa.

As dietas e os genótipos apresentaram diferenças significativas para rendimento de carcaça quente $(\mathrm{P}<0,05)$, corroborando a afirmação de Sañudo \& Sierra (1986) de que raça e manejo influenciam o rendimento de carcaça. $\mathrm{O}$ rendimento de carcaça quente na dieta de maior nível energético, com média de $49,74 \%$, foi $5,8 \%$ superior ao rendimento dos animais da dieta de menor energia. Resultados semelhantes foram observados por Mahgoub etal.(2000) ao testarem dietas com 2,39;2,47 e 2,74 McalEM/kg de MS na dieta de ovinos deslanados da raça Omani abatidos com peso médio de $30,65 \mathrm{~kg}$.

Os resultados observados nesta pesquisa para rendimento carcaça quente são próximos aos encontrados por Alves et al. (2003), que avaliaram diferentes densidades energéticas na dieta de cordeiros Santa Inês e obtiveram rendimento de carcaça quente médio de $48,43 \%$ com animais abatidos com 31,63 kg. Furusho-Garcia et al. (2000), no entanto, trabalhando com três dietas e três genótipos abatidos com $44 \mathrm{~kg}$, não encontraram influência $(\mathrm{P}>0,05)$ da dieta sobre o rendimento de carcaça quente e registraram média de 53,50\%. Ressalta-se que o peso de abate dos animais foi alto e, de acordo com Kemp et al. (1980), acréscimo no peso de abate aumenta o rendimento.

Entre os genótipos, a raça Morada Nova apresentou maior rendimento e diferiu $(\mathrm{P}<0,05)$ dos genótipos Santa Inês e mestiços Dorper $\times$ Santa Inês, que foram semelhantes entre si. Por sua vez, Furusho-Garcia et al. (2000), trabalhando com animais das raças Santa Inês e mestiços Texel $\times$ Bergamacia e Texel $\times$ Santa Inês abatidos com pesos médios de $43,76 \mathrm{~kg}$, não encontraram diferença no rendimento de carcaça quente entre genótipos. Nesse trabalho, a raça Morada Nova apresentou rendimento de carcaça quente de magnitude de $5,72 \%$ e foi $4,04 \%$ superior aos genótipos Santa Inês e mestiço Dorper $\times$ Santa Inês, provavelmente por ser um animal mais compacto e de trato digestivo menor.

As dietas mais energéticas proporcionaram maiores pesos de pescoço, paleta, costela, lombo e perna (Tabela 4), porém, em valores relativos $(\%)$, não diferiram $(\mathrm{P}>0,05)$ entre si.

$\mathrm{O}$ rendimento do corte pescoço, expresso em porcentagem, não foi influenciado $(\mathrm{P}>0,05)$ pelos genótipos. Porém, os cortes paleta e perna apresentaram diferenças significativas $(\mathrm{P}<0,05)$ entre os genótipos. Os resultados em percentual mostraram inferioridade de rendimentos de paleta e perna para a raça Morada Nova, em comparação à Santa Inês e aos mestiços, provavelmente por ser uma raça caracterizada pelo pequeno porte, de origem nativa, sem aperfeiçoamento prévio por meio de práticas seletivas para constituição de carcaça.

A porcentagem de costela foi influenciada $(\mathrm{P}<0,05)$ pelos genótipos, pois foi maior na raça Morada Nova, que diferiu significativamente da raça Santa Inês e dos mestiços Dorper $\times$ Santa Inês.

O pescoço e as costelas são de crescimento precoce e logo se estabilizam. Assim, animais com maior tendência a ganho de peso apresentam menor peso desses cortes e maior peso de perna.

O peso de lombo variou entre os genótipos, com médias semelhantes para os mestiços Dorper $\times$ Santa Inês e para o Morada Nova, porém maiores que a da raça Santa Inês. Essa menor proporção desse corte no genótipo Santa Inês provavelmente está relacionada ao maior porte desta raça em relação aos outros dois genótipos e ao fato de este músculo ser de crescimento tardio.

O peso do pescoço dos animais submetidos à dieta com maior concentração energética foi $12,24 \%$ superior aos

Tabela 3 - Rendimento biológico e de carcaça de ovinos de três genótipos terminados com dietas de dois níveis energéticos

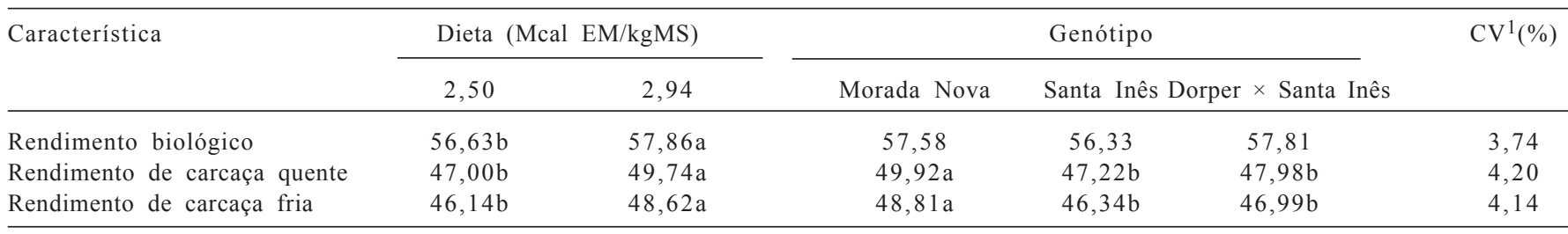

${ }^{1}$ Coeficiente de variação.

Médias seguidas de letra diferentes na mesma linha diferem significativamente entre si pelo teste Tukey a $5 \%$ de probabilidade. 
Tabela 4 - Média da composição regional (cortes comerciais) de carcaças resfriadas de ovinos de quatro genótipos

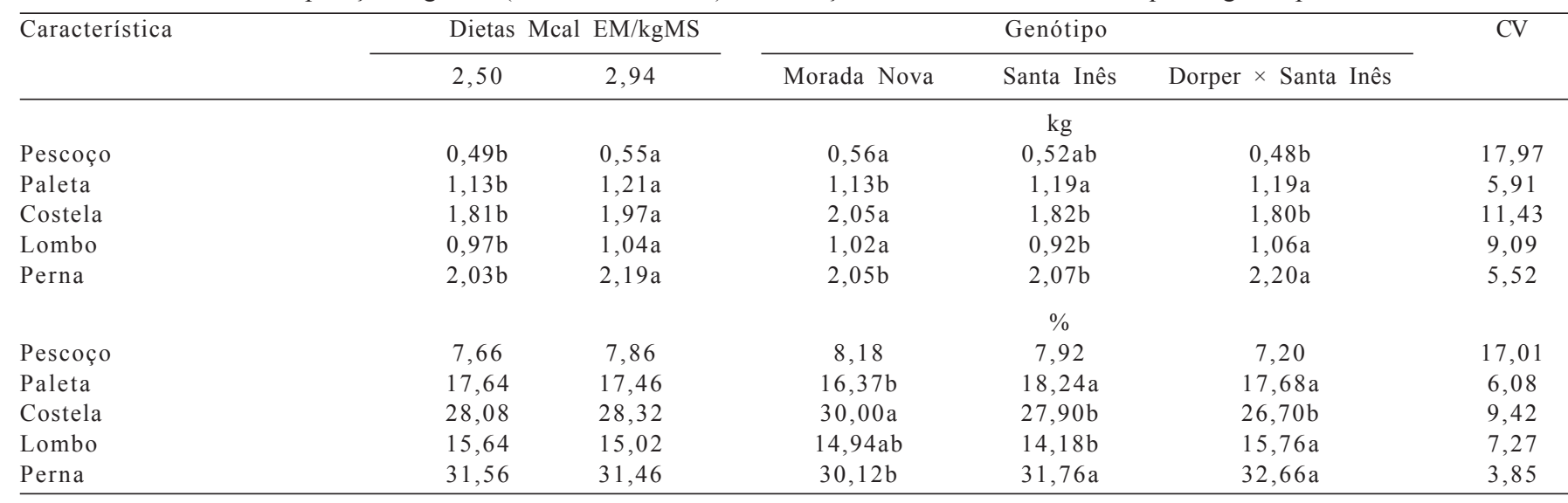

${ }^{1}$ Coeficiente de variação.

Médias seguidas da mesma letra, na mesma linha, não diferem significativamente entre si, pelo teste Tukey a $5 \%$ de probabilidade.

daqueles submetidos terminados com a dieta de menor nível energético. Entretanto, para o peso da costela, essa magnitude foi na ordem de $8,84 \%$ e para os cortes paleta, lombo e perna essa diferença foi em torno de $7,50 \%$ em favor da dieta com maior concentração energética.

A participação proporcional dos cortes em relação ao peso da carcaça fria mostrou comportamento diferente do observado para peso absoluto, uma vez que nenhum dos cortes sofreu influência das dietas $(\mathrm{P}>0,05)$. Agrupando os cortes, considerando a sua proporcionalidade em relação ao peso da carcaça fria, obteve-se a seguinte ordem: perna $>$ costela $>$ paleta $>$ lombo $>$ pescoço.

Gonzaga Neto et al. (2006), em pesquisa com cordeiros da raça Morada Nova em confinamento com dietas com três níveis de energia, encontraram valores de 9,92\% para rendimento de pescoço, $19,38 \%$ para paleta, $24,82 \%$ para costela, $11,81 \%$ em relação ao lombo e $33,88 \%$ para perna em relação à meia-carcaça.

O peso da paleta dos animais submetidos à dieta com maior nível energético foi $7,08 \%$ superior ao obtido com menor nível de energia. Saatci et al. (2003), avaliando o desempenho e as características de carcaça de cordeiros da raça Tuj submetidos a três dietas, encontraram para peso de paleta 2,$90 ; 3,03$ e 3,30 kg, diferença que não foi significativa e diferente do peso alcançado neste experimento.

O genótipo Santa Inês e os mestiços Dorper $\times$ Santa Inês foram semelhantes entre si $(\mathrm{P}>0,05)$ e superiores ao Morada Nova $(\mathrm{P}<0,05)$, numa magnitude de $5,31 \%$. Como a paleta éum corte muito valorizado no mercado, essa superioridade do Santa Inês e mestiço Dorper $\times$ Santa Inês beneficia o produtor, por agregar maior valor às carcaças. Cartaxo et al. (2009), trabalhando com os genótipos Santa Inês e mestiços Dorper $\times$ Santa Inês, encontraram resultados semelhantes aos desta pesquisa. Por outro lado, Cézar (2004) encontrou diferença significativa entre esses dois genótipos.

$\mathrm{O}$ efeito da dieta sobre os pesos médios do corte lombo foi significativo $(\mathrm{P}<0,05)$, uma vez que a média obtida com a dieta de maior densidade energética foi 7,22\% superior à de menor densidade energética. Esses resultados corroboram os divulgados por Moron-Fuenmayor \& Clavero (1999) em estudo envolvendo cordeiros submetidos a três manejos nutricionais, os quais encontraram valores variando de 0,23 a $0,37 \mathrm{~kg}$. Resultados diferentes dos obtidos nesta pesquisa foram divulgados por Saatci et al. (2003), que, ao estudarem cordeiros da raça Tuj submetidos a três dietas, não observaram diferença significativa para este corte.

Os cordeiros da raça Santa Inês apresentaram menor média de peso para o corte lombo, com $0,92 \mathrm{~kg}$, diferindo $(\mathrm{P}>0,05)$ dos outros dois grupamentos genéticos. Essa diferença foi de 10,87\% em relação à raça Morada Nova e $15,22 \%$ para os mestiços Dorper $\times$ Santa Inês. Esse resultado provavelmente está refletindo o que afirmam alguns pesquisadores, que o peso dos cortes é influenciado pela idade e raça dos animais.

O efeito do nível energético sobre as médias de peso da perna proporcionou diferença de $7,88 \%$ para a dieta com maior nível energético em relação àquela com menor nível energético, resultados semelhantes a esse foi encontrado por Saatci et al. (2003).

O peso da perna não variou entre as raças Morada Nova e Santa Inês e foram 7,32 e 6,28\% menores que os do genótipo Dorper $\times$ Santa Inês. Esse fato pode ser reflexo do cruzamento, envolvendo Dorper, raça especializada para produção de carne. Resultado semelhante foi divulgado por Abdulkhaliq et al. (2007), em trabalho com animais das raças Dorset, Texel e Suffolk. Por outro lado, Cartaxo et al. (2009), trabalhando 
com cordeiros das raças Santa Inês e mestiços Dorper $\times$ Santa Inês, não encontraram diferença significativa para peso de perna. De forma semelhante, Furusho-Garcia et al. (2003) também não verificaram diferença significativa $(\mathrm{P}>0,05)$ entre cordeiros das raças Santa Inês, mestiços Texel $\times$ Bergamácia e Texel $\times$ Santa Inês para peso da perna .

$\mathrm{Na}$ análise econômica das dietas em cada grupo genético, foram considerados o ganho de peso total dos cordeiros por dieta e por raça, o período de confinamento da cada tratamento, os custos da dieta e as despesas com vacinação e medicamento (Tabela 5 ).

Os níveis energéticos das dietas proporcionaram diferença $(\mathrm{P}<0,05)$ para margem bruta e a dieta de maior nível de energia, apesar do custo 5,50\% superior ao de menor energia, apresentou maior margem bruta, da ordem de $44,16 \%$, fato relacionado ao menor número de dias de confinamento (Tabela 2) obtido com essa dieta. Não houve diferença $(\mathrm{P}>0,05)$ entre os grupos genéticos para a margem bruta.

Cartaxo et al. (2009), trabalhando com cordeiros das raças Santa Inês e mestiços Dorper $\times$ Santa Inês terminados em confinamentos e abatidos com 36,75 e 35,87 dias de confinamento, respectivamente, encontraram valores para margem bruta de $\mathrm{R} \$ 6,20$ /animal para a raça Santa Inês e R \$ 8,13/animal para os mestiços Dorper $\times$ Santa Inês.

Tabela 5 - Resultados econômicos (real/animal) obtidos com as dietas (Mcal EM/kgMS) em cada grupo genético

\begin{tabular}{|c|c|c|c|c|c|}
\hline \multirow[t]{2}{*}{ Característica } & \multicolumn{2}{|c|}{ Dieta (Mcal EM/kgMS) } & \multicolumn{3}{|l|}{ Genótipo } \\
\hline & 2,50 & 2,94 & Morada Nova & Santa Inês & Dorper $\times$ Santa Inês \\
\hline Ganho de peso $(\mathrm{kg})$ & 12,05 & 12,57 & 13,55 & 11,46 & 11,92 \\
\hline Dieta kg MS (R\$)* & 0,37 & 0,39 & 0,38 & 0,38 & 0,38 \\
\hline Preço inicial do cordeiro $(\mathrm{R} \$)$ & 49,68 & 51,15 & 44,94 & 52,89 & 53,40 \\
\hline Preço final do cordeiro ( $\mathrm{R} \$$ ) & 85,83 & 88,86 & 85,59 & 87,27 & 89,16 \\
\hline Vacina e Medicamento ( $R \$)$ & 1,20 & 1,20 & 1,20 & 1,20 & 1,20 \\
\hline Margem bruta/cordeiro ( $\mathrm{R} \$$ ) & $7,88 \mathrm{~b}$ & $11,36 \mathrm{a}$ & 8,41 & 10,78 & 9,68 \\
\hline
\end{tabular}

*Farelo de milho: R\$ 0,33; Farelo de soja: R\$ 0,70; Farelo enriquecido de palma: R\$ 0,28; Feno de tifton: R\$ 0,37; Ureia: R\$ 0,88; Sal mineral: R\$ 0,80.

\section{Conclusões}

Os rendimentos de carcaça quente e fria são maiores em animais Morada Nova em comparação a animais Santa Inês e mestiços. Dietas de maior nível energético proporcionam melhores rendimentos e maiores pesos dos cortes comerciais. Em geral, a raça Morada Nova apresenta cortes comerciais compatíveis com os da raça Santa Inês e com os mestiços.

\section{Referências}

ABDULKHALIQ, A.M.; MEYER, H.H.; BUSBOOM, J.R. et al. Growth, carcass and cooked meat characteristics of lambs sired by Dorset rams heterozygous for the Callipyge gene and Suffolk and Texel rams. Small Ruminant Research, v.71, p.92-97, 2007.

ALMEIDA JR., G.A.; COSTA, C.; MONTEIRO, A.L.G. et al. Desempenho, características de carcaça e resultado econômico de cordeiros criados em creep feeding com silagem de grãos úmidos de milho. Revista Brasileira de Zootecnia, v.33, n.4, p.1048-1059, 2004.

ALVES, K.S.; CARVALHO, F.F.R.; VÉRAS, A.S.C. et al. Níveis de energia em dietas para ovinos Santa Inês: desempenho. Revista Brasileira de Zootecnia, v.32, n.6, p.1937-1944, 2003 (supl.2).

CARTAXO, F.Q.; CÉZAR, M.F.; SOUZA, W.H. et al. Características quantitativas da carcaça de cordeiros terminados em confinamento abatidos em diferentes condições corporais. Revista Brasileira de Zootecnia, v.38, n.4, p.697-704, 2009.

CÉZAR, M.F. Características de carcaça e adaptabilidade fisiológica de ovinos durante a fase de cria. 2004. $88 \mathrm{f}$. Tese (Doutorado em Zootecnia) - Universidade Federal da Paraíba, Areia.

CEZAR, M.F; SOUSA, W.H. Carcaças ovinas e caprinas obtenção, avaliação e classificação. 1.ed. Uberaba: Editora Agropecuária Tropical, 2007. 231p.

COLOMER-ROCHER, F. Los criterios de calidad de la canal: sus implicaciones biológicas. In: CURSO INTERNACIONAL SOBRE LA PRODUCCIÓN DE OVINO DE CARNE, 1986 Zaragoza, v.2, 66p. (mimeo.)

FURUSHO-GARCIA, I.F.F.; PEREZ, J.R.O.; OLIVEIRA, M.V. Características de carcaça de cordeiros Texel x Bergamácia, Texel x Santa Inês e Santa Inês Puros, terminados em confinamento, com casca de café como parte da dieta. Revista Brasileira de Zootecnia, v.29, n.1, p.253-260, 2000.

FURUSHO-GARCIA, I.F.F.; PEREZ, J.R.O.; TEIXEIRA, J.C. Componentes de carcaça e composição de alguns cortes de cordeiros Texel x Bergamácia, Texel x Santa Inês e Santa Inês Puros, terminados em confinamento, com casca de café como parte da dieta. Revista Brasileira de Zootecnia, v.32, n.6, p.1999-2006, 2003 (supl.).

GONZAGA NETO, S.; SILVA SOBRINHO, A.G.; ZEOLA, N.B.L. et al. Características quantitativas da carcaça de cordeiros deslanados Morada Nova, em função da relação volumoso:concentrado na dieta. Revista Brasileira de Zootecnia, v.35, n.3, p.1487-1495, 2006.

HUIDOBRO, F.R.; CAÑEQUE, V.; ONEGA, E. et al. Morfologia de la canal ovina. In: CAÑEQUE, V.; SAÑUDO, C. (Eds.) Metodologia para el estudo de la calidad de la canal y de la carne em ruminantes. Madrid: INIA, 2000. p.81-102. 
KEMP, J.D.; MAHYUDDIN, M.; ELY, D.G. et al. Effect of feeding systems slaughter weigth and sex on organoleptic properties, and fatty acid composition of lambs. Journal of Animal Science, v.51, n.2, p.321-330, 1980 .

MAHGOUB, O.; LU, C.D.; EARLY, R.J. Effects energy density on feed intake, body weight gain and carcass chemical composition of Omani growing lambs. Small Ruminant Research, v.37, p.35-42, 2000 .

MORON-FUENMAYOR, O.E.; CLAVERO, T. The effect of feeding system on carcass characteristics, non-carcass components and retail cut percentages of lambs. Small Ruminant Research, v.34, p.57-64, 1999.

NATIONAL RESEARCH COUNCIL - NRC. Nutrient requirements of sheep. Washington, D.C.: National Academy Press, 1985. p.95.

NERES, M.A.; MONTEIRO, A.L. G.; GARCIA, C.A. et al. Forma física da ração e pesos de abate nas características de carcaça de cordeiros em creep feeding. Revista Brasileira de Zootecnia, v.30, n.3, p.948-954, 2001 (supl. 1).
SAATCI, M.; YILDIZ, S.; KAYA, I. New rearing systems for Tuj (Tushin) lambs. Small Ruminant Research, v.50, p.23-27, 2003.

SANTOS, C.L.; PÉREZ, J.R.O. Cortes comerciais de cordeiros Santa Inês. In: ENCONTRO MINEIRO DE OVINOCULTURA, 1. 2000, Lavras. Anais... Lavras: UFLA, 2000. p.149-168.

SAÑUDO, C.; SIERRA, I. Calidad de la canal en la especie ovina. Revista Ovis, v.1, p.127-153, 1986.

STATISTICAL ANALYSIS SYSTEM - SAS. SAS user's guide: Stat, Version 6., 4.ed. Cary: SAS Institute, 1996. 955p.

TABOSA, J.N.; ARAÚJO, E.C.; SILVA, F.G. et al. Elaboração do farelo enriquecido de palma forrageira e sua utilização na alimentação de ruminantes. In: ENCONTRO NACIONAL DE PRODUÇÃP DE CAPRINOS E OVINOS, 1., 2006, Campina Grande. Anais... Campina Grande: SNPA/UFPB, 2006.

VÉRAS, R.M.L.; FERREIRA, M.A.; CAVALCANTE, C.V.A. et al. Substituição do milho por farelo de palma forrageira em dietas de ovinos em crescimento. Desempenho. Revista Brasileira de Zootecnia, v.34, n.1, p.249-256, 2005. 